\title{
Miscelánea
}

\section{Entrevista a Amaia Ibarrola Arana, enfermera española que ejemplifica la disposición y el gran dinamismo de los jóvenes profesionales españoles que van a trabajar a otros países}

Cómo citar esta entrevista en edición digital: Siles González, J. (2014) Entrevista a Amaia Ibarrola Arana, enfermera española que ejemplifica la disposición y el gran dinamismo de los jóvenes profesionales españoles que van a trabajar a otros países. Cultura de los Cuidados (Edición digital) 18, 39. Disponible en: http://dx.doi.org/10.7184/cuid.2014.39.15>

Correo electrónico: aibarrolaa@gmail.com

\section{Cuéntanos algos sobre tus principios como} persona y como profesional: nacimiento, dónde se desarrolló tu infancia?

Nací el dos de junio de 1981, es decir, tengo 33 años en Vitoria (Álava), tengo un hermano menor (nos llevamos dos años) y desde que cumplí los 7 años nos fuimos a vivir a Pamplona ya que mis padres son navarros, mi madre de Pamplona y mi padre de Falces (un pueblo del sur de Navarra). Estudié en la Ikastola San Fermín hasta la universidad, obviamente en euskera, ahora lo tengo algo olvidado...

Personalmente siempre me he parecido mas a mi padre a la hora de ser más aventurera, de buscar experiencias fuera de casa, de hecho con 11 años mis padres me enviaron a Irlanda durante un mes a casa de una familia para aprender inglés, después continué año tras año pero esta vez a Inglaterra. La experiencia estuvo muy bien, bueno y el inglés algo mejoró...

Desde pequeña quise estudiar Veterinaria, es una espina clavada que tengo ahí, pero bueno al final decidí estudiar enfermería en la Universidad de Navarra. Con prácticas desde el primer año en la Clínica Universitaria, yo ya tenia claro que me quería ir fuera de España a trabajar a ver que se movía por ahí...

\section{¿Dónde realizaste tus estudios de enfermería? \\ En la Universidad de Navarra, acabe en 2005.}

Relátanos una síntesis de tu experiencia laboral previa a tu salida de España.

Yo trabajé durante la carrera de enfermería en una pescadería. Estuve unos años trabajando durante el verano en las temporadas altas. Hasta realice un curso para poder cortar pescado!! Como enfermera mi primer trabajo fue directamente en Inglaterra.

Acabé la carrera en mayo, en junio fui a Madrid para realizar una entrevista con varios hospitales del Reino Unido ya que anteriormente existía un convenio entre España y Reino Unido. Me acuerdo que había muchísima gente, las condiciones de trabajo eran buenas, te pagaban el viaje, te recogían en el aeropuerto etc.. Eran para hospitales repartidos por todo UK, yo elegí Cardiff, Gales. La selección de personal se realizaba en un hotel, durante todo el día, nos hicieron una presentación de los distintos hospitales públicos (NHS) y luego tú elegías el que más te gustaba.

Fue mi primera entrevista en inglés como enfermera. Y me seleccionaron. En dos meses estaba ya preparando maletas para incorporarme. 
Qué trabajos has desarrollado fuera de España ¿te ha costado adaptarte?

Como ya he comentado, mi primer trabajo fue en un hospital en Cardiff, Gales. Comencé como "new qualified Nurse", es decir, recién salida de la carrera. Estuve trabajando en planta de rehabilitación geriátrica, mi trabajo consistía en ayudar a las auxiliares a preparar los baños de los pacientes, repartir la medicación, realizar curas, etc..

Me costó adaptarme por la barrera del idioma obviamente. Puedes saber inglés pero hasta que no estás delante del paciente o con tus compañeros que solo hablar inglés, no te das cuenta de lo que cuesta realmente y ese "sentirse extranjero" que nunca lo había vivido como profesional. No es lo mismo estar de estudiante que tienes tus responsabilidades "limitadas" que como enfermera firmando con tu "pin number".

Para mi esa fue la etapa mas dura, los comienzos nunca son fáciles pero más cuando no tienes experiencia y hay mil términos en otro idioma a los que no estas acostumbrada. Y a partir de ahí mil anécdotas que contar claro..

\section{Nos podrías decir las principales diferencias y semejanzas a nivel de enfermería en tus dife- rentes trabajos}

Cuando yo empecé a trabajar como enfermera en UK vi que las enfermeras inglesas estaban mas centradas en la teoría y en firmar mil papeles que en ser mas resolutivas a la hora de sacar el trabajo. También la sub especialización que existe dentro de las enfermeras. Yo me acuerdo de mis practicas, en planta, hacíamos curas, cambiábamos sueros, calculabas los balances hídricos, cogías vías, etc...

En Uk no. Para cada cosa había una enfermera especializada en esa área, y tus funciones estaban limitadas. Me acuerdo que en UK nunca llegué a coger una via, había que esperar al medico residente para que lo hiciera.
El trabajo en equipo. Otra de las cosas que a lo largo del tiempo trabajando como enfermera noté diferencia. En España nos apoyamos mas unas a otras. Somos mas un equipo para el bien del paciente. En cambio en el extranjero, tanto UK como Arabia Saudí lo primero es cubrirte las espaldas individualmente. Puedes pedir ayuda claro pero siempre pensando por ti primero.

\section{Cuéntanos cómo fue lo de tu experiencia en} Arabia como enfermera y como mujer

A pesar de la idea generalizada que tiene la mayoría de la gente sobre Arabia Saudí y su "trato hacia las mujeres" yo lo puedo contar desde mi experiencia es que estuve muy a gusto, me trataron muy bien y en ningún momento tuve la sensación de ser "menos" respecto a mi trabajo como enfermera y como mujer. Es cierto que tienes que saber sus costumbres pero en el hospital King Faisal en Riyadh aprendí muchísimo.

Soy enfermera de quirófano y anestesia y trabajo instrumentado cirugías. Mi especialidad es ginecología, obstetricia, pediatría, transplantes renales, cirugía general, endoscopias, la verdad que he pasado por la mayoría de las especialidades quirúrgicas. En Riyadh aproveche la oportunidad de formación en mas especialidades y familiarizarme con equipos quirúrgicos como el "Da Vinci", equipos laparoscópicos inalámbricos , y muchos mas avances tecnológicos que no había visto hasta entonces.

Trabajé con compañeros de diferentes nacionalidades, religiones y culturas, médicos cirujanos europeos (la minoría), jordanos, saudíes, etc. y éramos un equipo. Es verdad que cuesta adaptarse pero nadie dijo que iba a ser fácil.

\section{¿Qué te gustaría hacer en el futuro?}

Me gustaría seguir conociendo más hospitales, diferentes formas de trabajar sobre un mismo objetivo, el paciente. Seguir aprendiendo sin miedo y que te reconozcan esos aprendizajes. 
De momento mi sitio está en Londres, pero no descarto trabajar en países como Qatar, Bahrein, etc..

Por ultimo me encantaría poder ayudar a aquellas personas que intentan encontrar su sitio profesionalmente, yo cuando salí fuera de España no encontré mucho apoyo a nivel profesional, y cuando decidí irme a Arabia saudí incluso menos. Me gusta dar orientación a aquellos que pidan información, desde mi experiencia claro está.

Y también no me cansaré de repetir lo importante que es hablar idiomas!!!! El ingles para empezar pero cualquier idioma es una gran ayuda para el futuro si queremos salir fuera. Yo estoy aprendiendo árabe y francés....

\section{Biblioteca comentada}

CON TODO EL BARRO DE LA VIDA.

Tonino Albalatto (2014)

Raspabook editorial, Murcia. 69 páginas.

ISBN 13: 978-84-941372-3-5

Cómo citar esta entrevista en edición digital:

Siles González, J. (2014) Tonino Albalatto

y "Con todo el barro de la vida". Cultura

de los Cuidados (Edición digital) 18, 39.

Disponible en: http://dx.doi.org/10.7184/

cuid.2014.39.16>

Correo electrónico: Antonio Marín Albalate <amalbalate@yahoo.es>

Tonino Albalatto es un poeta de raíces profundas y múltiples. Aunque al menos se le conocen tres diferentes ramificaciones a poco que rastreemos su misterioso origen (Antonio Albalate, Juan Cartagena y Tonino Albalatto), su ya enorme caudal lírico confluye en una obra poética donde se deja translucir un perfil único que revela la forma genuina y sistemática propia de un auténtico maestro del verso. La obra de Albalatto es tan amplia como intensa y sería imposible resumir los premios recibidos a lo largo de su dilatada trayectoria poética (más de una treintena de poemarios). También destaca como dinamizador cultural desarrollando su actividad en el marco de la asociación "Diván" coordinando y prota-

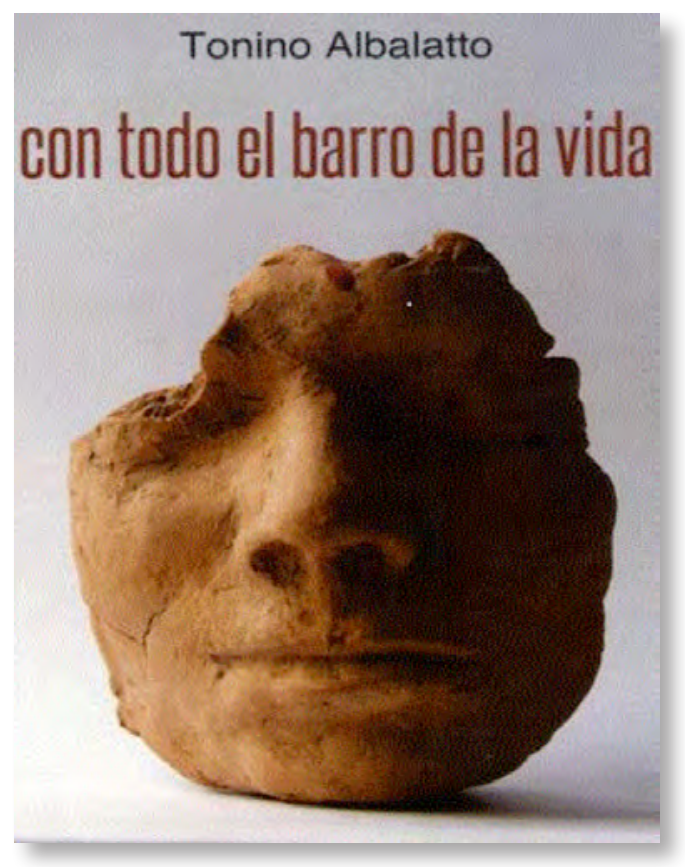

gonizando encuentros literarios y culturales. $\mathrm{Ha}$ coordinado ediciones dedicadas a personajes de la cultura como Joan Manuel Serrat, Luis Eduardo Aute, Leopoldo María Panero, José Hierro, José Agustín Goytisolo, Josefina Soria, Carmen Conde, etc.

En "Con todo el barro de la vida" se nos aparece un Tonino Albalatto procedente del pequeño pueblo italiano de Sorenacco (Padua) regalándonos 41 poemas traducidos por Ángel 